\title{
Oestrogen formation and connective tissue growth factor expression in rat granulosa cells
}

\author{
Christopher R Harlow, Angela C Bradshaw, Michael T Rae, Kirsty D Shearer and Stephen G Hillier \\ University of Edinburgh Centre for Reproductive Biology, Queen's Medical Research Institute, 47 Little France Crescent, Edinburgh EH16 4TJ, UK \\ (Requests for offprints should be addressed to C R Harlow; Email: c.harlow@ed.ac.uk)
}

\begin{abstract}
Ovarian follicular development involves continual remodelling of the extracellular matrix (ECM) forming the basement membrane and intercellular framework that support granulosa cell (GC) growth and differentiation. Insight into the molecular regulation of ovarian ECM remodelling is potentially translatable to tissue remodelling elsewhere in the body. We therefore studied the link between a gene marker of ECM remodelling (connective tissue growth factor (CTGF)) and oestrogen biosynthesis (cytochrome $\left.\mathrm{P} 450_{\text {aromatase }}\left(\mathrm{P} 450_{\text {arom }}\right)\right)$ in rat granulosa cells. To determine if a cause-effect interaction exists, we used semi-quantitative in situ hybridisation to analyse patterns of CTGF and P450 arom mRNA expression and immunohistochemistry to detect CTGF protein localisation throughout follicular development, and tested the actions of CTGF on oestrogen biosynthesis and oestradiol on CTGF mRNA expression in isolated GC in vitro. CTGF mRNA levels in GC rose gradually through small preantral (SP) and small antral (SA) stages of development to a maximum (fivefold higher) in large antral (LA) follicles. In preovulatory (PO) follicles, the CTGF mRNA level fell to $30 \%$ of that in SP follicles. P450 arom mRNA also increased (threefold in LA relative to SP) throughout antral development follicles, but in contrast to CTGF continued to increase (12-fold) in PO follicles. In the cumulus oophorus of PO follicles, the residual GC CTGF mRNA expression increased with proximity to the oocyte, being inversely related to $\mathrm{P} 450_{\text {arom. }}$. Elsewhere in the follicle
\end{abstract}

wall, there was a mural-to-antral gradient of CTGF mRNA expression, again inversely related to $\mathrm{P} 450_{\text {arom }}$. Immunohistochemistry showed CTGF protein localisation broadly followed mRNA expression during follicular development, although the protein was also present in the theca interna and ovarian surface epithelium. Gradients in CTGF expression across the cumulus oophorus and follicle wall were similar to those observed for mRNA with CTGF protein expression being greatest in proximity to the oocyte. Treatment of isolated GC from preantral and SA follicles with recombinant human CTGF $(1-100 \mathrm{ng} / \mathrm{ml})$ did not affect basal or FSHstimulated GC aromatase activity. However, in the absence of FSH, oestradiol $\left(10^{-7}-10^{-5} \mathrm{M}\right)$ stimulated CTGF mRNA expression up to twofold. Conversely, FSH $(10 \mathrm{ng} / \mathrm{ml})$ alone reduced CTGF mRNA expression by $40 \%$ and combined treatment with FSH and oestradiol further suppressed CTGF to $10 \%$ of the control value. The oestrogen receptor (ER) antagonist, ICI 182780 blocked the stimulatory and inhibitory effects of oestradiol, suggesting a specific ER-mediated mode of action on CTGF. Therefore, CTGF gene expression in GC is under local control by oestrogen whose effect (positive or negative) is modulated by FSH. This helps explain why gene expression of CTGF and $\mathrm{P} 450_{\text {arom }}$ diverge in FSH-induced $\mathrm{PO}$ follicles and has implications for oestrogenic regulation of CTGF formation elsewhere in the body.

Journal of Endocrinology (2007) 192, 41-52

\section{Introduction}

Ovarian follicular development requires sustained formation and breakdown of the extracellular matrix (ECM) with collateral development and disruption of local vasculature. A paracrine factor newly implicated in this process in the ovary is connective tissue growth factor (CTGF, CCN2; Slee et al. 2001). CTGF is a member of the multi-domain gene family known as CCN (ㄷTGF/Cysteine-rich 61/Nephroblastoma) and has been identified in numerous epithelial-derived cells with multiple roles connected with tissue remodelling (Brigstock 1999). Through mediation or modulation of
TGF $\beta$ action, CTGF regulates connective tissue synthesis in fibroblasts (Duncan et al. 1999), osteoblasts (Pereira et al. 2000), chondrocytes (Eguchi et al. 2001), vascular smooth muscle cells (Fan et al. 2000) and renal mesengial cells (Goppelt-Struebe et al. 2001).

We previously showed that rat granulosa cells in preantral and early antral follicles abundantly express CTGF (Slee $e t$ al. 2001), which is upregulated by TGF $\beta$ superfamily members and androgens but downregulated by follicle stimulating hormone (FSH) in vitro (Harlow et al. 2002). In addition, we observed an apparent inverse relationship, detected by in situ hybridisation, between CTGF and cytochrome P450 aromatase 
$\left(\mathrm{P} 450_{\text {arom }}\right)$ mRNA expression (i.e. oestrogen synthesis) in the developing rat follicle (Slee et al. 2001). Ovarian CTGF immunoreactivity has previously only been observed in the pig (Wandji et al. 2000), where it paralleled mRNA expression in granulosa, theca and vascular endothelial cells of the theca and corpus luteum. Several ECM components have been characterised during mouse follicular development (Berkholtz et al. 2006). For example, fibronectin and type IV collagen are detectable in theca, stroma and basement membrane of small preantral (SP) follicles and increase as the follicle size increases (Berkholtz et al. 2006). Thus, based on the pattern of CTGF expression during folliculogenesis in rat (Slee et al. 2001, Harlow et al. 2002), luteal development in pig (Wandji et al. 2000) and ECM component expression during mouse follicle development (Berkholtz et al. 2006), granulosa cell-derived CTGF likely plays a critical role in theca cell recruitment, follicle growth and corpus luteum vascularisation.

The intrafollicular role of oestrogens in rodents remains unclear, with conflicting reports on whether oestrogens directly affect the development of follicles in vivo (for reviews, see Hillier et al. 1980, Rosenfeld et al. 2001). In vitro studies suggest that oestrogens can stimulate $\mathrm{P} 450_{\text {arom }}$ activity and induce gonadotrophin receptors (Hsueh et al. 1984). In the light of our previous observation that androgens modulate CTGF mRNA expression (Harlow et al. 2002), here we ask if oestrogen locally affects $C T G F$ gene expression and vice versa in rat ovarian follicles. Results reveal evidence for a direct action of oestrogen on CTGF gene and protein expression in the developing preovulatory (PO) follicle.

\section{Materials and Methods}

\section{Hormones and tissue culture reagents}

Diethylstilbestrol (DES), oestradiol, testosterone and BSA (fraction V) were obtained from Sigma. Oestrogen receptor (ER) antagonist ICI 182780 was obtained from Tocris Crookson Ltd (Bristol, UK). Recombinant human FSH (rhFSH; $3860 \mathrm{IU} / \mathrm{mg}$ ) was donated by Dr C Howles (Serono Laboratories, Inc. Welwyn Garden City, UK). rhCTGF was provided by Fibrogen, Inc. (South San Francisco, CA, USA). Culture medium was medium 199 with 25 mM HEPES, without phenol red, supplemented with $2 \mathrm{mM}$ L-glutamine, $50 \mathrm{IU} / \mathrm{ml}$ penicillin, $50 \mu \mathrm{g} / \mathrm{ml}$ streptomycin (all from Invitrogen Ltd) and $0 \cdot 1 \%(\mathrm{w} / \mathrm{v})$ BSA. Donor calf serum and Dulbecco's PBS were also obtained from Invitrogen Ltd.

\section{Animals}

Twenty-one-day-old female Wistar rats (Charles River Laboratories, Inc., Margate, Kent, UK) were housed under temperature-controlled conditions on a $12 \mathrm{~h}$ light: $12 \mathrm{~h}$ darkness cycle and fed rat chow available ad libitum. Handling and treatment of animals were according to the Animals (Scientific Procedures) Act, 1986. For in situ hybridisation and immunohistochemistry studies (see below), rats were either left untreated or injected with equine chorionic gonadotropin (eCG; $10 \mathrm{IU}$ ) and ovaries collected $48 \mathrm{~h}$ later. Six animals were used for each experiment. For in vitro studies, proliferating but essentially undifferentiated, granulosa cells were induced by giving twice daily s.c. injections of DES (2 mg/day) in ethanol:propylene glycol (5:95) to stimulate preantral/early antral follicular development. Thirty animals were used in each experiment.

\section{Granulosa cell isolation and culture}

Animals were killed by asphyxiation with $\mathrm{CO}_{2}$ and the ovaries removed. Granulosa cells were isolated by puncturing follicles with a 25 gauge hypodermic needle and gently expelling the cells into medium. Pooled cells were centrifuged, resuspended in fresh medium and their viability assessed by counting a Trypan blue-stained preparation in a haemocytometer. Cell viability was $25-30 \%$. Tissue culture grade $24-$ well plastic dishes (Corning, Inc., Corning, NY, USA) were precoated with $0.25 \mathrm{ml}$ donor calf serum and washed twice with Dulbecco's PBS $(0.5 \mathrm{ml})$ before inoculating with $0.25 \mathrm{ml}$ culture medium containing $1 \times 10^{5}$ viable cells. Following overnight preincubation at $37^{\circ} \mathrm{C}$ in a humidified atmosphere containing $5 \% \mathrm{CO}_{2}$ in air, $0.25 \mathrm{ml}$ prewarmed medium containing hormone treatments was added (24-36 wells per treatment) and the incubation continued for $48 \mathrm{~h}$. Aromatase activity was measured in a separate group of four culture wells after the incubation by washing the cell monolayers twice with prewarmed Dulbecco's PBS and adding fresh medium containing $1 \mu \mathrm{M}$ testosterone as substrate. This medium was collected after a further 3-h incubation and assayed for oestradiol by RIA (Hillier \& de Zwart 1982).

\section{In situ hybridisation}

Ovaries were fixed in 4\% paraformaldehyde in PBS and embedded in paraffin blocks. Following digestion with proteinase $\mathrm{K}$ and acetylation, the sections $(10 \mu \mathrm{m})$ were hybridised (overnight incubation at $55^{\circ} \mathrm{C}$ ) with cRNA probes generated from cDNA templates labelled with $\left[{ }^{35}\right.$ S]UTP (Amersham International) using an RNA transcription kit (Promega). Slides were washed in buffers of decreasing salt concentrations, dehydrated through ethanol gradients and processed for liquid emulsion autoradiography (Kodak NTB-2). After exposure for 3 weeks at $4{ }^{\circ} \mathrm{C}$, slides were developed, counterstained with haematoxylin and taken for photomicrography. Sense cRNA probes were used as a control for non-specific binding.

\section{CTGF immunohistochemistry}

Five-micrometre sections of ovaries of eCG-treated rats were dewaxed and antigen retrieval was achieved by pressure cooking in $10 \mathrm{mM}$ citrate buffer. Serum blocking was with normal goat serum in PBS-BSA followed by avidin-biotin 
block. Primary antibody (rabbit anti-CTGF raised against full-length $38 \mathrm{kDa}$ glycosylated human CTGF, kindly donated by Dr David Brigstock, Center for Cell and Vascular Biology, Children's Research Institute, Columbus, OH, USA) was applied at $40 \mu \mathrm{g} / \mathrm{ml}$ overnight followed by secondary antibody (biotinylated goat anti-rabbit 1:500 in NGS/PBS/BSA, Molecular Probes; Invitrogen) for $30 \mathrm{~min}$. Antigen binding was localised using Streptavidin Alexa 546 (Molecular Probes; Invitrogen) diluted in the ratio of 1:200 in PBS for $1 \mathrm{~h}$ followed by nuclear counterstaining with Sytox Green (Molecular Probes; Invitrogen) 1:1000 in PBS for $5 \mathrm{~min}$. Slides were mounted in Permafluor and visualised using a LSM510 confocal microscope with argon laser (505-550 nm filter) and helium-neon1 laser with long-pass $560 \mathrm{~nm}$ filter. For negative control slides, the primary antibody was replaced with the same concentration of antibody that had previously been incubated overnight with a fivefold excess of recombinant human CTGF (Fibrogen) to block active binding sites.

\section{$R N A$ isolation and northern blot analysis}

Total RNA was isolated from rat granulosa cell monolayers using RNAzolB (Tel-Test, Friendswood, TX, USA), with the following modification of the manufacturer's instructions. Cell monolayers were drained of excess medium and $0 \cdot 1 \mathrm{ml}$ RNAzolB added to each well. The lysates from 12 wells were pooled and mixed with $0 \cdot 2 \mathrm{ml}$ chloroform. This mixture was added to a Phase Lock Gel tube (Eppendorf AG, Hamburg, Germany) and the aqueous phase separated by centrifugation according to the manufacturer's instructions.

Total RNA ( $5 \mu \mathrm{g})$ was size-fractionated by electrophoresis on a $1 \%$ agarose-formaldehyde denaturing gel for $3 \mathrm{~h}$ at $80 \mathrm{~V}$ and visualised with ethidium bromide. The RNA was transferred overnight to a nylon membrane (Hybond-N, Amersham Pharmacia Biotech) which was then baked for $2 \mathrm{~h}$ at $80^{\circ} \mathrm{C}$. Rat CTGF transcripts were detected by probing with a cDNA clone corresponding to nucleotides 934-1340 of the full-length rat CTGF cDNA (Xu et al. 2000; Genebank accession number: AF120275), as described previously (Slee et al. 2001). Northern blot hybridisation was performed using standard methods. Hybridisation was in Ultrahyb buffer (Ambion (Europe) Ltd, Huntingdon, Cambs, UK) at $42{ }^{\circ} \mathrm{C}$ using ${ }^{32} \mathrm{P}$-labelled probes (Redivue, Amersham Pharmacia Biotech). Posthybridisation washes were two 5-min washes in $2 \times$ SSC and two 15-min washes in $0 \cdot 1 \times$ SSC each with $0 \cdot 1 \%$ SDS at $42{ }^{\circ} \mathrm{C}$. Hybridisation was quantified by electronic autoradiography using an Instant Imager (Packard, Downers Grove, IL, USA), and exposed to autoradiographic film (XAR-5, Eastman Kodak Co.) for $2-24 \mathrm{~h}$ at $-70{ }^{\circ} \mathrm{C}$. After stripping, blots were reprobed with a rat $18 \mathrm{~S}$ rRNA cDNA probe (donated by Dr G Scobie, MRC Human Reproductive Sciences Unit, Edinburgh, UK) to allow correction for gel loading and transfer. Northern blots were quantified by electronic autoradiography (Instant Imager, Packard, Downers Grove, IL, USA) with normalisation of mRNA abundance to 18S rRNA. Experimental results are presented relative to unstimulated, control values.

\section{RNA extraction and TaqMan real-time PCR analysis}

RNA was extracted from granulosa cells using RNeasy minispin columns (Qiagen Ltd) as per the manufacturer's protocol, including DNase treatment $(1 \mathrm{U})$ on the column. Portions $(1 \mu \mathrm{l})$ of purified RNA were removed for quantification and quality assessment, using the Agilent 2100 Bioanalyser system for total RNA in combination with RNA6000nano chips (Agilent Technologies, Cheshire, UK). Only RNA that displayed intact $18 \mathrm{~S}$ and $28 \mathrm{~S}$ peaks was reverse transcribed to cDNA for real-time PCR analysis. This quality control step was included for each experimental run to avoid generation of false negative results due to RNA degradation prior to and during extraction steps, and also as a quantification method to ensure equal amounts of RNA were transcribed in each RT reaction.

\section{Real-time PCR analysis}

Total RNA (200 ng) was reverse transcribed (random hexamer kit; Applied Biosystems), and $2 \mu \mathrm{RT}$ mix was analysed. The final reaction volume was $25 \mu \mathrm{l}$ containing $300 \mathrm{nmol} / 1$ primers and $200 \mathrm{nmol} / \mathrm{l}$ TaqMan hybridisation probe (Biosource UK Ltd). Primers and probes were designed using Primer-Express software (Perkin-Elmer, Beaconsfield, Bucks, UK). Target mRNA was quantified in relation to $18 \mathrm{~S}$ rRNA abundance in each sample, with suitable positive-control RNA (rat liver total RNA (Ambion (Europe) Ltd) and in-house prepared rat placental mRNA), and negative controls consisting of RT-negative (RNA template with no reverse transcriptase enzyme), and $\mathrm{RT}-\mathrm{H}_{2} \mathrm{O}$ (water in place of RNA template) samples generated at the time of reverse transcription of samples, plus a TaqMan reaction negative control where cDNA was replaced with water. The sequences of primers and probe were as follows: forward primer: CGCCAACCGCAAGATTG; reverse primer: ACACGGACCCACCGAAGAC; probe: TGCCCTGCCAAAGATGGTGCAC. The primer/ probe set was validated prior to use.

\section{Image analysis}

In situ hybridisation slides were visualised using bright- and dark-field microscopy and images captured using a chargecoupled device (CCD) camera. Openlab v2.08 (Improvision Ltd, Coventry, UK) was used as a platform to create an automated image analysis system for the measurement of follicle diameter and hybridisation signal intensity. Diameter was determined by drawing around the outside surface of the granulosa compartment. To ensure that maximum follicle diameter was measured, the analysis was restricted to sections passing through the oocyte. The programme calculated the mean diameter from the area measured. Follicles were divided into five class sizes based on their mean diameter, identified as follows: small preantral (SP), 50-117 $\mu \mathrm{m}$; large preantral (LP), 118-165 $\mu \mathrm{m}$; small antral (SA), 166-273 $\mu \mathrm{m}$; large antral (LA), 274-449 $\mu \mathrm{m}$; PO, 450-600 $\mu \mathrm{m}$. Silver grain intensity was assigned a value on an arbitrary scale from 1 (black) to 255 (white). For cumulus oophorus readings, signal intensity was 

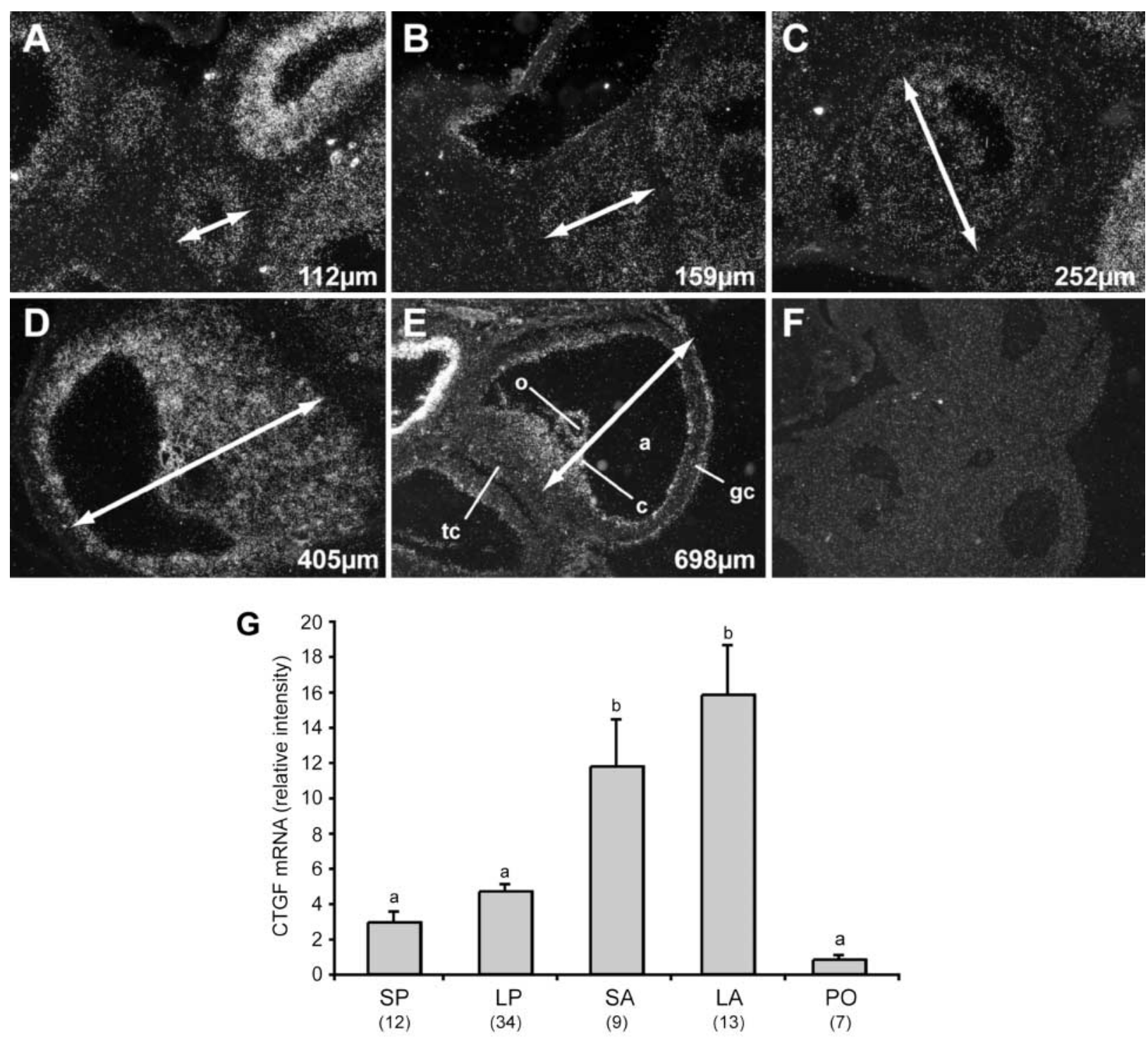

Follicle class

Figure 1 Granulosa cell CTGF mRNA expression in relation to follicular maturity in rat ovary. In situ hybridisation analysis using a $\mathrm{S}^{35}$-labelled CTGF cRNA probe was carried out on ovarian sections from untreated and eCG-treated immature rats containing follicles at varying stages of follicular maturation, as described in Materials and Methods. (A-F) Digital photomicrographs of CTGF in situ hybridisation images. (A) Small preantral follicle, (B) large preantral follicle, (C) small antral follicle, (D) large antral follicle, (E) preovulatory follicle, and (F) sense strand control depicting follicles ranging from small preantral to large antral. Most intense signal was observed in the large antral follicles. Diameter of the granulosa cell (gc) compartment (arrow) is displayed in bottom right. a, antral cavity; c, cumulus; o, oocyte; tc, theca cell compartment. (G) Quantitative analysis of CTGF in situ hybridisation data from granulosa cell compartment of ovarian follicles: SP, small preantral; LP, large preantral; SA, small antral; LA, large antral; PO, preovulatory. Mean \pm s.E.M. Number of follicles analysed is given at the base of each bar. One-way ANOVA showed a significant effect of follicle size $(F=17 \cdot 24 ; \mathrm{d} . \mathrm{f} .=4,70 ; P<0 \cdot 0001)$. Bars with different superscript letters are significantly different $(P<0 \cdot 001$, Fisher's PLSD).

read sequentially at 15 equidistant locations across the cumulus granulosa cell layer, progressing from the mural granulosa cell layer (position 1) to cells adjacent to the oocyte (position 15) in five PO follicles. Measurements from elsewhere comprised nine successive readings from the mural (position 1) to antral (position 9) granulosa cell layers of the same follicles.

\section{Data analysis}

Data were analysed using one-way ANOVA with Fisher's protected least-square differences (PLSD) to determine the effects of individual treatments. Image analysis data were compared by one-way ANOVA and general linear model 

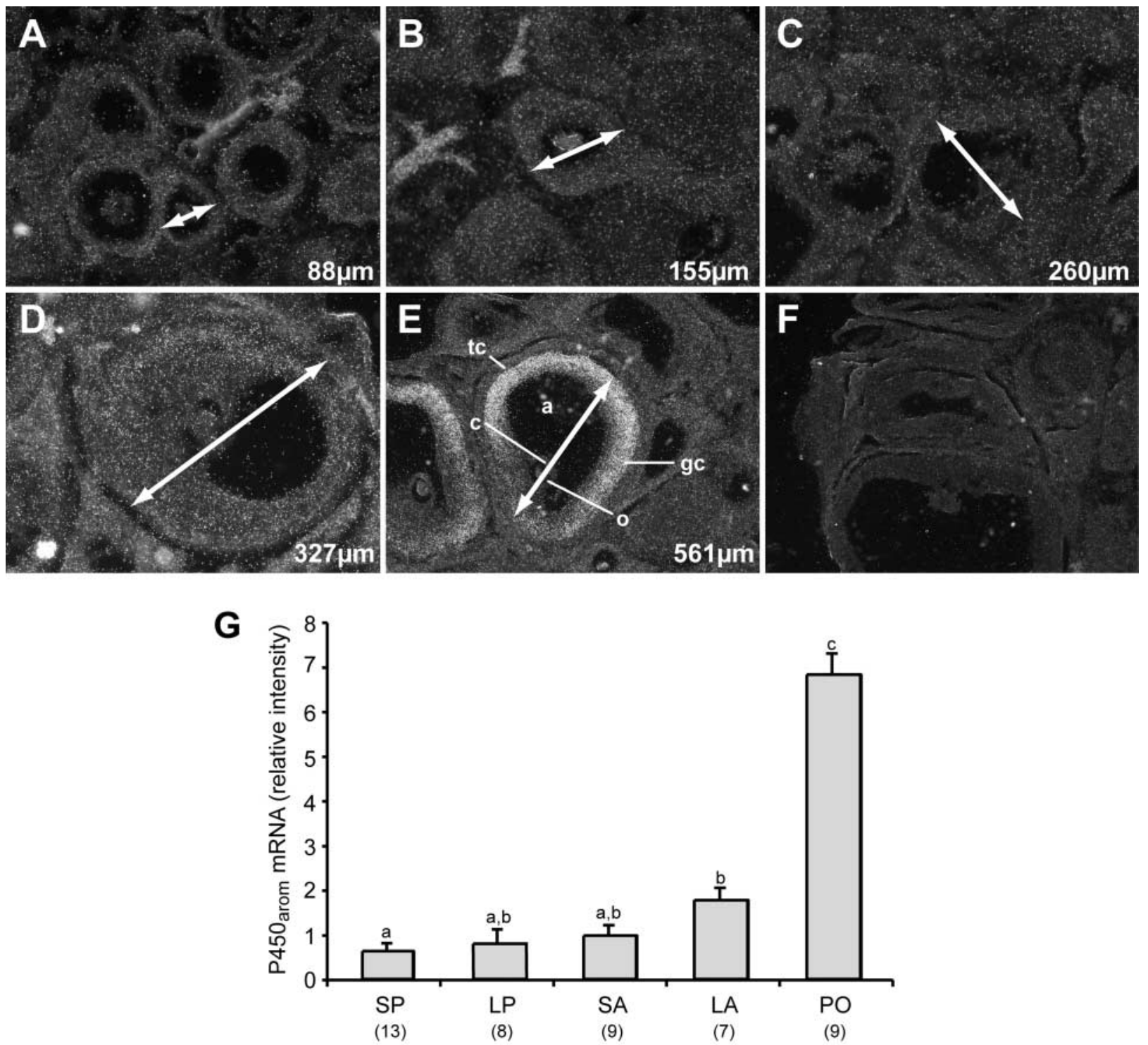

Follicle class

Figure 2 Granulosa cell P450 arom mRNA expression in relation to follicular maturity in rat ovary. In situ hybridisation analysis using a $\mathrm{S}^{35}$-labelled $\mathrm{P} 450_{\text {arom }}$ CRNA probe was carried out on ovarian sections from untreated and eCG-treated immature rats containing follicles at varying stages of follicular maturation, as described in Materials and Methods. (A-F) Digital photomicrographs of P450 arom in situ hybridisation images from (A) small preantral follicle, (B) large preantral follicle, (C) small antral follicle, (D) large antral follicle, (E) preovulatory follicle, and (F) sense strand control depicting follicles from large preantral to preovulatory stages. Most intense signal was observed in the preovulatory follicles. Diameter of the granulosa cell (gc) compartment (arrow) is displayed in bottom right. a, antral cavity; c, cumulus; o, oocyte; tc, theca cell compartment. (G) Quantitative analysis of $\mathrm{P} 450_{\text {arom }}$ in situ hybridisation data from granulosa cell compartment of ovarian follicles: SP, small preantral; LP, large preantral; SA, small antral; LA, large antral; PO, preovulatory. Mean \pm s.E.M. Number of follicles analysed is given at the base of each bar. One-way ANOVA showed a significant effect of follicle size $(F=62 \cdot 6 \overline{5}$, d.f. $=4,41, P<0 \cdot 0001)$. Bars with different superscript letters are significantly different $(P<0 \cdot 05$, Fisher's PLSD).

to dissect the main effects and interactions. Differences with $P<0 \cdot 05$ were regarded as significant. TaqMan results from different experiments were normalised relative to control (untreated) cells, and the statistical analysis was performed on the raw data using one-way ANOVA with Fisher's PLSD to determine the effects of individual treatments.

\section{Results}

Spatiotemporal relationships between CTGF and P450 arom $m R N A$ expression

CTGF mRNA abundance increased gradually from low levels in SP follicles to maximum levels that were fivefold 
higher in LA follicles (Fig. 1). In PO follicles, CTGF mRNA decreased to $30 \%$ of that observed in SP follicles (Fig. 1). By contrast, $\mathrm{P} 450_{\text {arom }}$ did not increase in LP and SA follicles, increased threefold in LA follicles, but increased a further fourfold in PO follicles (Fig. 2).

Measurement of signal intensity across the cumulus oophorus of PO follicles showed a gradual linear increase in CTGF mRNA from cells on the basement membrane to those in the vicinity of the oocyte, with an inverse relationship to $\mathrm{P} 450_{\text {arom }}$ (Fig. 3). Elsewhere in the follicle wall, the rise in CTGF mRNA from mural to antral granulosa cells was exponential in nature and again inversely related to $\mathrm{P} 450$ arom (Fig. 4).

\section{Spatiotemporal changes in localisation of CTGF protein}

Granulosa cell CTGF protein localisation was detected immunohistochemically at all stages of follicular development (Fig. 5) but was greatest in SA follicles (Fig. 5D). Specific CTGF immunostaining was also noted in theca cells of some follicles (Fig. 5B and D) and in the ovarian surface epithelium
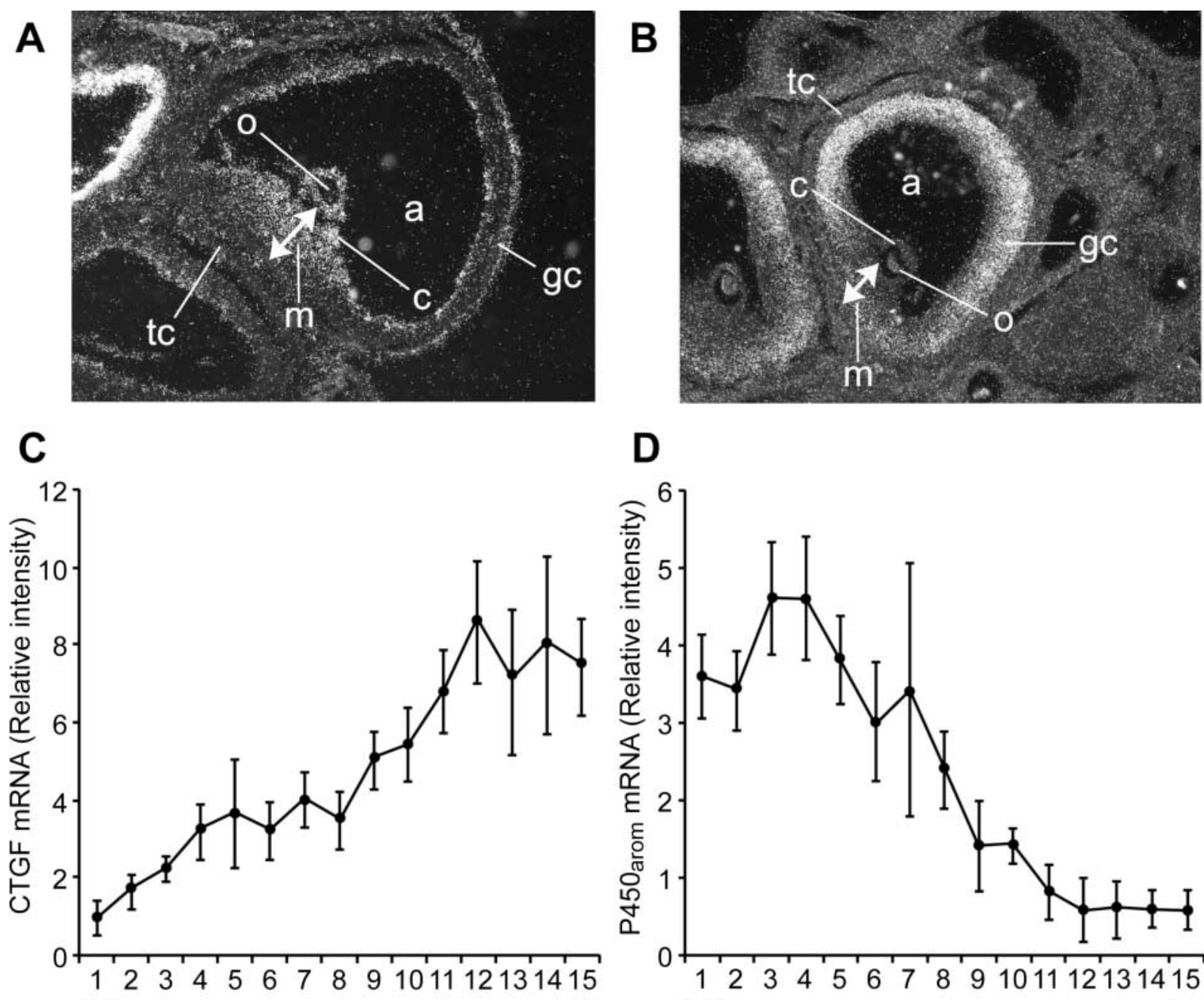

(m)

(c)

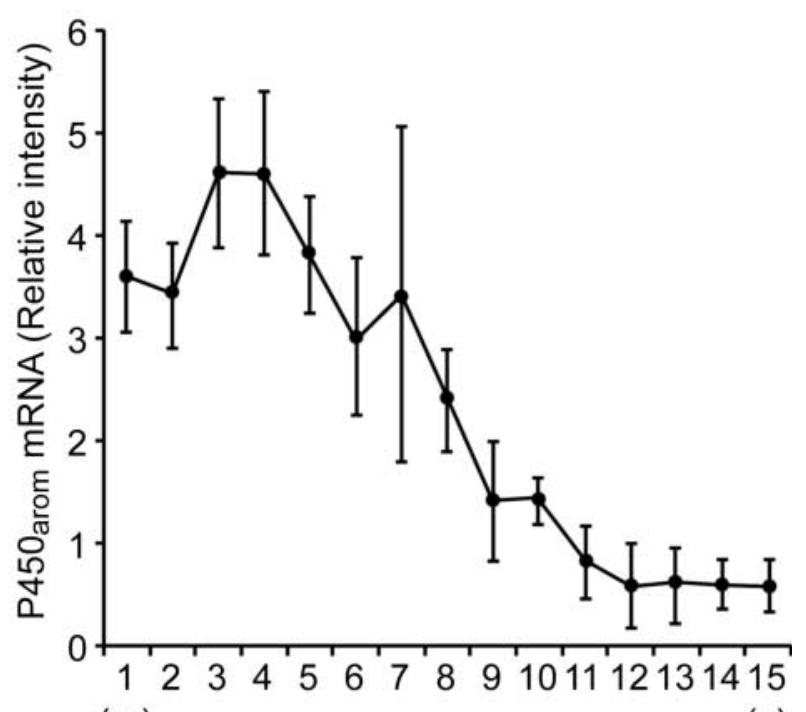

(m)

(c)

\section{Location in follicle wall}

Figure 3 Reciprocal relationship between CTGF and P450arom mRNA expression in cumulus oophorus granulosa cells of preovulatory follicles. In situ hybridisation analysis using a $\mathrm{S}^{35}$-labelled CTGF and P450 arom CRNA probes was carried out on ovarian sections from eCG-treated immature rats, as described in Materials and Methods. Digital photomicrographs of (A) CTGF and (B) P450 arom in situ hybridisation showing the gradient of CTGF mRNA intensity across the cumulus oophorus from mural (m) to cumulus (c) granulosa cells. a, antrum; gc, granulosa cells; o, oocyte; tc, theca cells. The arrows show representative sampling regions. (C) CTGF and (D) P450 arom signal intensities read sequentially from 15 equidistant locations across the cumulus granulosa cell layer, progressing from the mural granulosa cell layer (position 1) to the corona radiata (position 15; see Materials and Methods) Mean \pm s.E.M., $n=5$. One-way ANOVA showed a significant effect of distance (CTGF: $F=4 \cdot 33$, d.f. $=4,41, P<0 \cdot 0001$; $P 450$ arom: $F=8 \cdot 12$, d.f. $=14,60, P<0 \cdot 0001$ ). 

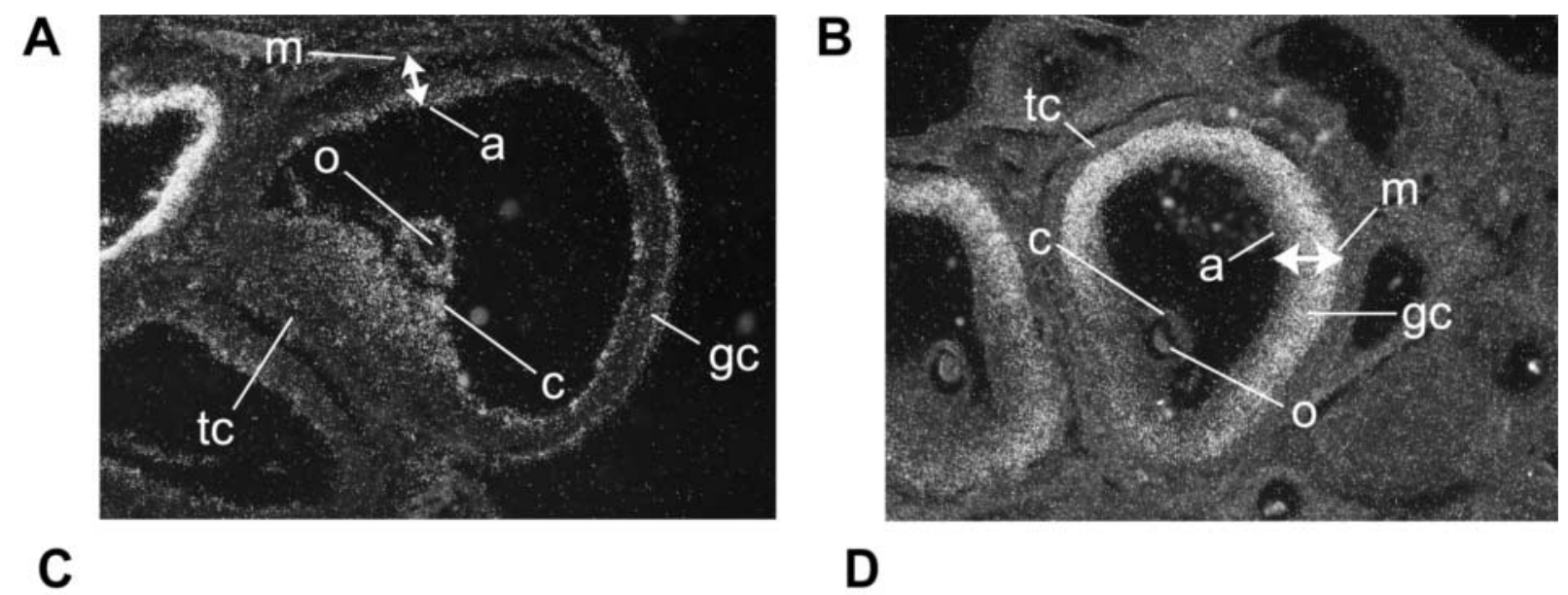

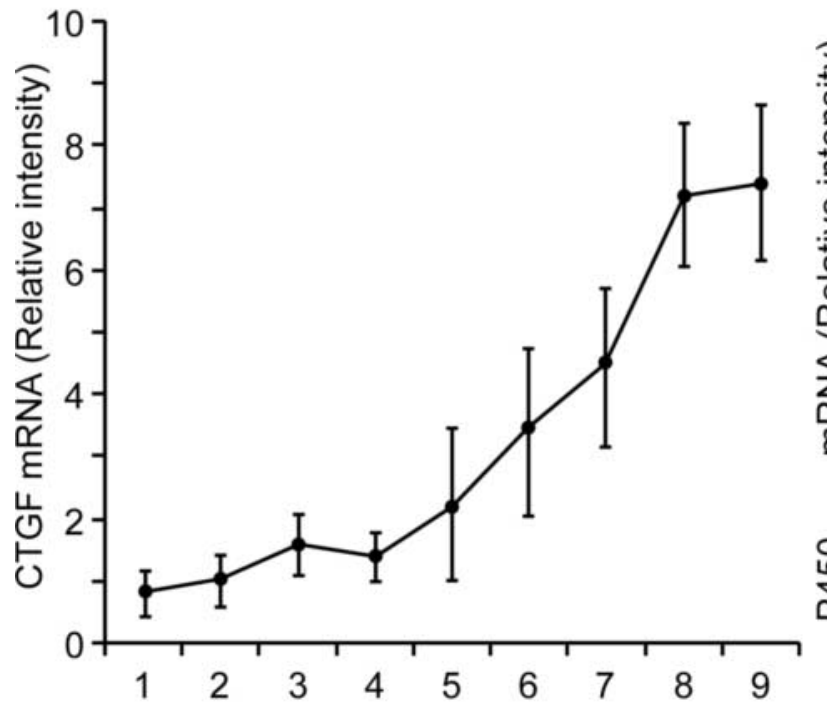

(m)

(a)

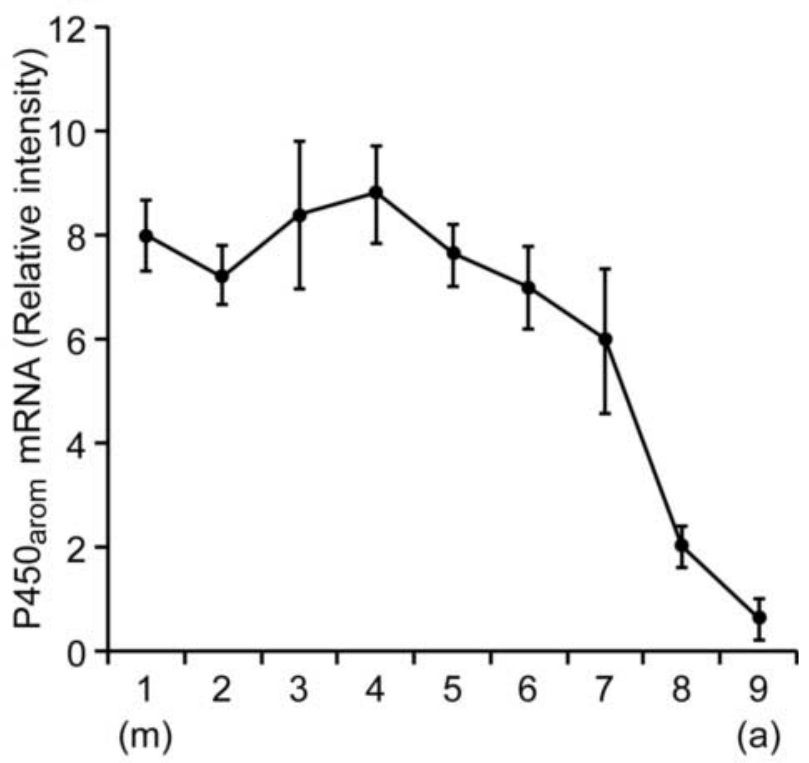

\section{Location in follicle wall}

Figure 4 Reciprocal relationship between CTGF and P450 arom mRNA expression across the walls of preovulatory follicles. In situ hybridisation analysis using a $\mathrm{S}^{35}$-labelled CTGF and P450 arom CRNA probes was carried out on ovarian sections from eCG-treated immature rats, as described in Materials and Methods. Digital photomicrographs of (A) CTGF and (B) P450 arom in situ hybridisation showing the gradient of CTGF mRNA intensity across the preovulatory follicle wall from mural (m) to antral (a) granulosa cells. gc, granulosa cells; o, oocyte; tc, theca cells. The arrows show representative sampling regions. (C) CTGF and (D) P450 arom signal intensities read sequentially from nine equidistant locations progressing from the mural (position 1) layer to the antral (position 9) granulosa cell layer (see Materials and Methods). Mean \pm s.E.M., $n=5$. One-way ANOVA showed a significant effect of distance (CTGF: $F=6 \cdot 85$, d.f. $=8,36, P<0 \cdot 0001 ; P 450$ arom: $F=10 \cdot 60$, d.f. $=8,36, P<0 \cdot 0001)$.

(Fig. 5B). Apparent intense staining of oocytes was nonspecific (Fig. 5C and D). In PO follicles, there was intense specific staining of cumulus cells and a clear gradient of expression from coronal/antral to mural granulosa cells (Fig. 5F). Overall expression was less in PO than in SA follicles (Fig. 5D and F).

In vitro studies

The above in situ hybridisation and immunohistochemistry results show that in $\mathrm{PO}$ follicles that have been exposed to maturing levels of FSH in vivo, and responded by increased expression of $\mathrm{P} 450_{\text {arom }}$, there is a dramatic reduction in expression of CTGF mRNA and protein. To investigate the interaction of these genes further, and to assess whether CTGF has a direct effect on aromatase activity, we cultured granulosa cells with rhCTGF in the absence or presence of $\mathrm{FSH}$, mimicking the environment in preantral/early antral and $\mathrm{PO}$ follicles respectively. To examine the effects of oestradiol on CTGF mRNA expression, we also tested the effects of oestradiol in the presence or absence of FSH to mimic the conditions that occur after PMSG treatment, and 

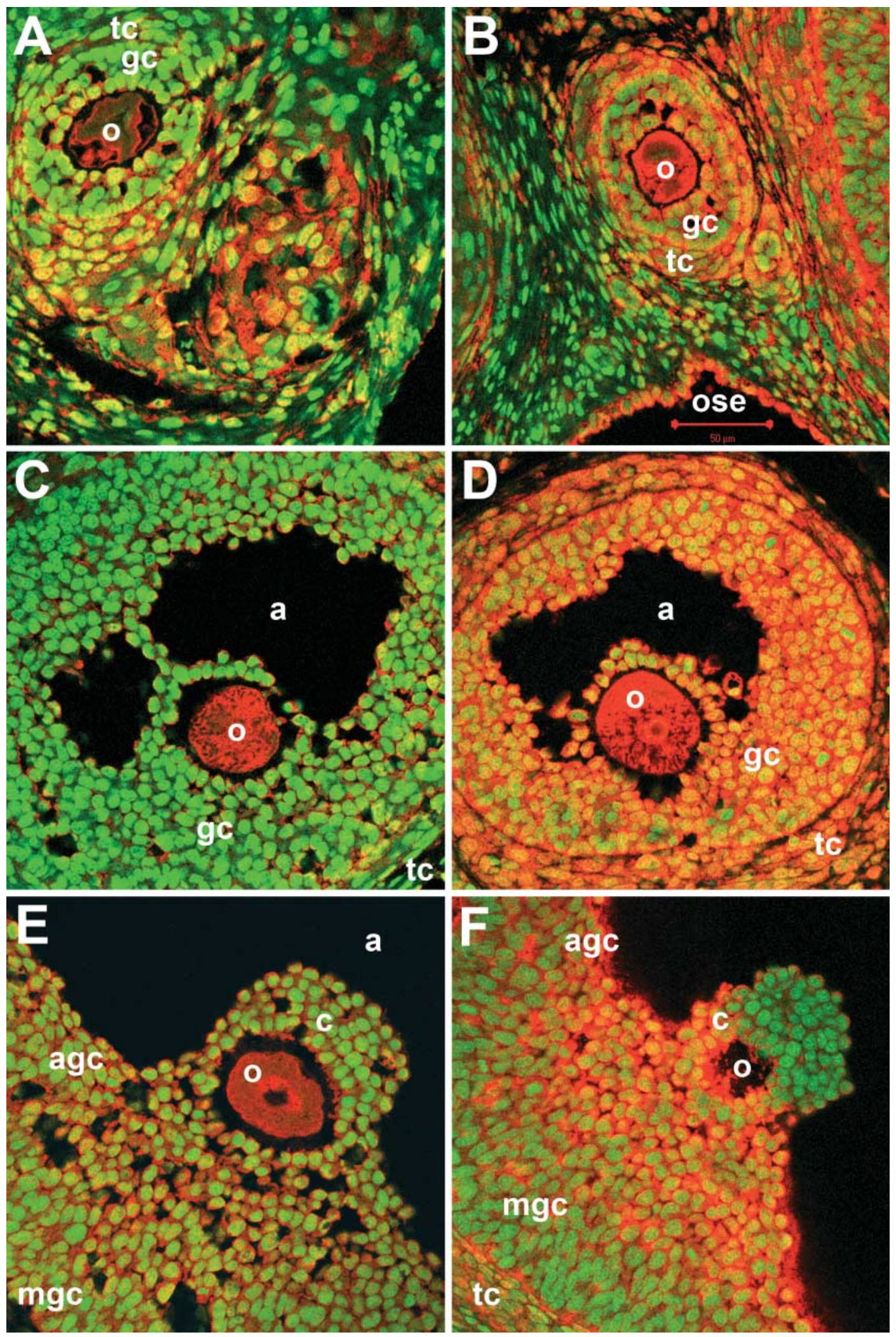
in the presence or absence of an ER antagonist to assess whether the effect of oestradiol was ER mediated.

Effects of CTGF on granulosa cell $P 450_{\text {arom }}$ enzymic activity

To test for direct effects of CTGF on granulosa cell function, granulosa cells from preantral/SA follicles were cultured for $48 \mathrm{~h}$ with CTGF $(1-100 \mathrm{ng} / \mathrm{ml})$ in the presence or absence of a fixed dose of FSH $(10 \mathrm{ng} / \mathrm{ml})$ before determining aromatase enzyme activity. In four out of four experiments, the presence of CTGF had no effect on basal- or FSH-induced activity (data not shown).

\section{Effects of oestradiol on CTGF $m R N A$ expression}

To test the direct effects of oestrogen on CTGF mRNA expression, preantral/SA granulosa cell cultures were treated with oestradiol $\left(10^{-7}-10^{-5} \mathrm{M}\right)$ with and without $\mathrm{FSH}$ $(10 \mathrm{ng} / \mathrm{ml})$ before quantifying CTGF mRNA expression by northern analysis. Oestradiol alone caused a dose-dependent increase in CTGF mRNA expression which was significant at $10^{-5} \mathrm{M}$ (Fig. 6). However, in the presence of FSH (which alone significantly reduced CTGF mRNA expression by $40 \%$ ), oestradiol caused dose-dependent inhibition of CTGF mRNA expression, which was also significant at a dose of $10^{-5} \mathrm{M}$ (Fig. 6).

\section{ER-mediated oestradiol action on CTGF $m R N A$ expression}

To establish an ER-mediated mode of oestradiol action on granulosa cell CTGF mRNA expression, preantral/SA granulosa cells were treated in vitro with oestradiol and/or FSH in the presence and in the absence of the selective ER antagonist ICI 182 780, using real-time RT-PCR analysis of CTGF mRNA as readout. As shown in Fig. 7, the increase in CTGF mRNA induced by $10^{-5} \mathrm{M}$ oestradiol was blocked by an equimolar concentration of ICI $182780\left(10^{-5} \mathrm{M}\right)$. The inhibitory effect of FSH on CTGF mRNA levels in the presence and in the absence of oestradiol was also partially ameliorated by the presence of ICI 182780 (Fig. 7).

\section{Discussion}

These results are novel in three ways. First, we quantify a clear reciprocal relationship between CTGF and $\mathrm{P} 450_{\text {arom }}$ gene expression in ovarian granulosa cells. Secondly, we establish a spatio-temporal pattern of CTGF mRNA expression and protein localisation that strongly implicates CTGF in peri/postovulatory follicular physiology. Thirdly, we

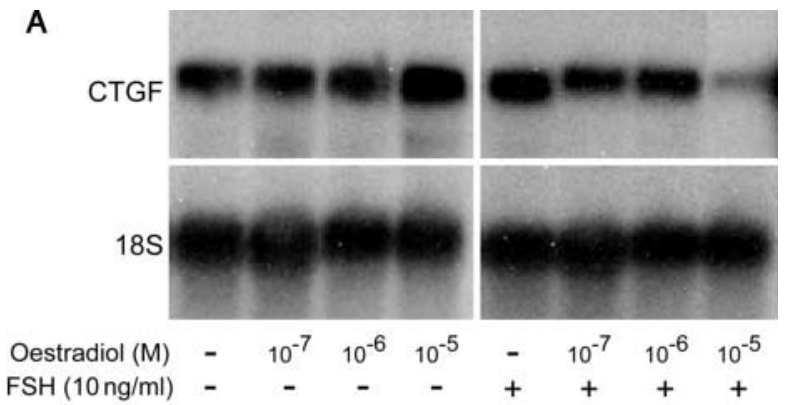

B

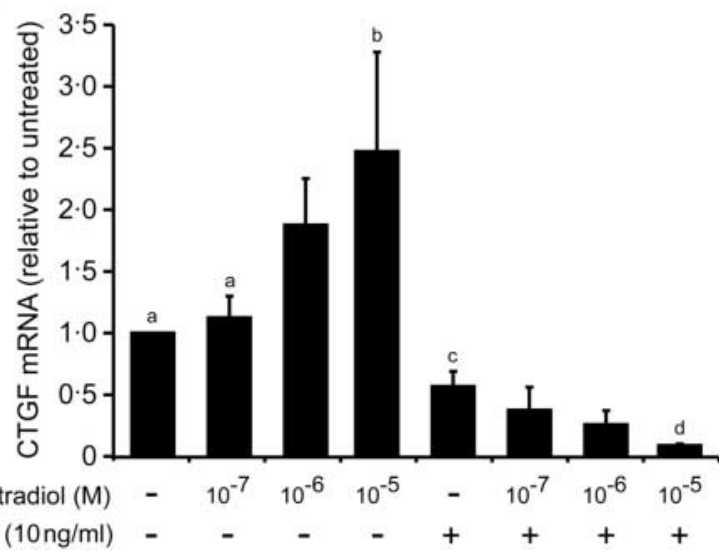

Figure 6 Oestrogenic regulation of granulosa cell CTGF mRNA expression. Granulosa cells from PA/SA follicles in immature rat ovaries were cultured for $48 \mathrm{~h}$ with oestradiol and/or FSH, as indicated, then total RNA was extracted for northern analysis of CTGF mRNA. (A) Autoradiogram of a typical northern blot showing CTGF mRNA compared with the signal for 18S rRNA (18S). Due to the large variation in the intensity of the CTGF mRNA signal between treatments with and without FSH, different exposure times were required for the two arms of the experiment (without FSH, $8 \mathrm{~h}$; with $\mathrm{FSH}, 48 \mathrm{~h}$ ). (B) Composite quantitative data from three separate experiments. Bars indicate the mean \pm s.E.M. CTGF mRNA intensity relative to the signal for $18 \mathrm{~S}$ measured by electronic autoradiography. All data were normalised to the control value. ANOVA showed a significant effect of treatment $(F=6 \cdot 41$, d.f. $=7,16, P=0 \cdot 001$ ). Significant effects comparing individual treatments are indicated by different superscript letters $(P<0 \cdot 05$, Fisher's PLSD).

demonstrate a direct ER-mediated mode of oestradiol action on granulosa cell CTGF mRNA expression.

Concerning the relationship between CTGF and $\mathrm{P} 450_{\text {arom }}$, our quantitative in situ hybridisation results quell any doubt that these genes might be reciprocally related in PO follicles. Not only are they temporally linked in the sense that as follicles become PO, their granulosa cells show overall massively reduced expression of CTGF in

Figure 5 Immunohistochemical analysis of CTGF protein localisation in rat ovary. Fluorescent double-antibody immunohistochemistry, using rabbit anti-human CTGF primary antiserum, as described in Materials and Methods. Digital photomicrographs showing the distribution of immunoreactive CTGF in A, B small preantral, C, D small antral and E, F preovulatory follicles. A, C and E were from sections in which the primary antibody was preabsorbed with a fivefold excess of CTGF protein. a, antrum; agc, antral granulosa cells; c, cumulus cells; gc, granulosa cells; mgc, mural granulosa cells; o, oocyte; ose, ovarian surface epithelium; tc, theca cells. Scale bar $=50 \mu \mathrm{m}$. 


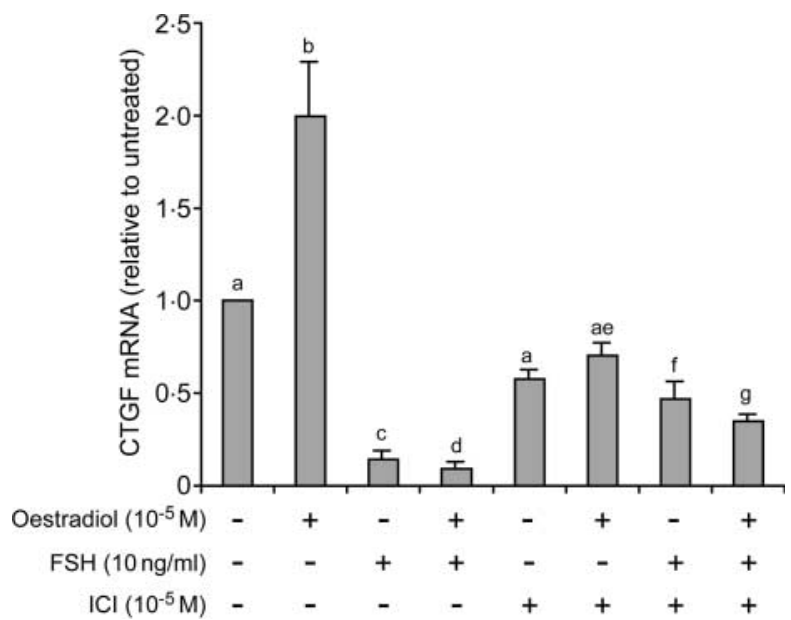

Figure 7 Blockade of oestradiol effects on granulosa cell CTGF mRNA expression by the ER antagonist ICI 182,780 (ICI). Granulosa cells from PA/SA follicles in immature rat ovaries were cultured for $48 \mathrm{~h}$ with the treatments indicated. Total RNA was extracted and analysed for CTGF mRNA by quantitative real-time RT-PCR as described in Materials and Methods. Results are expressed as the mean ( \pm s.E.M.) of five experiments. ANOVA showed a significant effect of treatment $(F=2 \cdot 824$, d.f. $=7,31, P=0 \cdot 02)$. Significant effects comparing individual treatments are indicated by different superscript letters $(P<0 \cdot 05$, Fisher's PLSD).

the face of increased expression of $\mathrm{P} 450_{\text {arom }}$, but also a reciprocal pattern of residual expression persists within the follicle wall. Most notably, CTGF mRNA expression and protein localisation persist in antrally located granulosa cells and those closest to the oocyte, implying a role for CTGF in the remodelling of the follicle wall associated with extrusion of the oocyte and formation of the corpus luteum.

The role of CTGF in follicular and luteal physiology seems unlikely to include direct effects on $\mathrm{P} 450_{\text {arom }}$ expression. Instead, we favour stimulation of CTGF expression by oestrogen. In the uterus, there is evidence that oestradiol can upregulate CTGF mRNA in glandular epithelium (Rageh et al. 2001), and the related CCN family member, Cyr61 (CCN1) is upregulated in human myometrial explants by oestradiol (Sampath et al. 2001). We found no effect of CTGF on oestradiol production in vitro despite being able to show that the CTGF added to our culture system was active in stimulating matrix metalloproteinase- 2 activity by granulosa cells (AC Bradshaw unpublished observations). Therefore, oestradiol biosynthesis appears not to be affected by biologically active levels of CTGF in vitro. Conversely, we found a modest effect of oestradiol on CTGF mRNA levels, consistent with the studies in the uterus. The level of oestradiol required to elicit an effect is within the range measured in rat follicular fluid (Fujii et al. 1983). Furthermore, the inhibition by ICI 182780 of oestradiol-stimulated CTGF mRNA, strongly points to an ER-mediated effect.

The stimulatory effect of oestradiol on CTGF mRNA expression by immature granulosa cells could explain the associated rise in $\mathrm{P} 450_{\text {arom }}$ and CTGF in follicles that occurs up to the LA stage but not the abrupt decline in CTGF observed in PO follicles at the time of maximum P450arom expression. The latter, and the inverse relationship between CTGF and P450 arom across the granulosa cell compartment, suggest an interaction between FSH and oestradiol to downregulate CTGF, which is confirmed in the present study in vitro. Since these culture experiments were carried out on granulosa cells from preantral/early antral follicles, they should have been a relatively homogeneous population of immature cells strongly expressing CTGF. However, the inhibition of CTGF expression by oestradiol in vitro may not reflect a parallel situation in vivo, where multiple positive regulators, including theca-derived androgen (Harlow et al. 2002) would be expected positively to impact CTGF expression.

CTGF protein was detected at all stages of follicular development and, unlike mRNA, was present in both granulosa and theca cells of follicles up to SA stage, as well as in the ovarian surface epithelium. There was evidence for an increase in distribution of protein from SP to SA follicles with a decline in PO follicles. This pattern is very similar to that observed during porcine follicular development (Wandji et al. 2000). Since CTGF mRNA is generally expressed only at low abundance in thecal cells relative to granulosa cells, we interpret the presence of immunoreactive CTGF protein due to formation in granulosa cells. Based on the established roles of CTGF in collagen biosynthesis, cell motility and angiogenesis, it can be predicted that the theca is a paracrine target of granulosa-derived CTGF (Harlow et al. 2002). We previously proposed that granulosa-derived CTGF is one of the main signals for formation of the thecal compartment when follicles form and begin to grow. A continuing role for CTGF in the extensive thecal remodelling required during antral stages of follicular development seems equally likely, particularly in light of the recent finding that key ECM markers, such as collagen IV and fibronectin appear to be developmentally regulated in the mouse follicle (Berkholtz et al. 2006). In this connection, CTGF is implicated in the deposition of collagen, through its role in modulating lysyl oxidase (Hong et al. 1999), a crucial enzyme required for cross-linking of collagen monomers (Smith-Mungo \& Kagan 1998). We also found lysyl oxidase to be developmentally regulated in the rat follicle (Harlow et al. 2003).

Previous studies have shown a gradient of $\mathrm{P} 450_{\text {arom }}$ protein expression across the rat $\mathrm{PO}$ follicle wall, with intensity declining centripetally (Turner et al. 2002). Here, this pattern was confirmed at the mRNA level, inversely related to CTGF mRNA and protein. The gradient in CTGF expression is intriguing, and highlights the probable compartmentalisation within the granulosa layer. However, the biological significance of these findings is unclear. CTGF is implicated in collagen synthesis: for example, CTGF stimulates lysyl oxidase enzyme activity and collagen deposition in human gingival fibroblasts (Hong et al. 1999). Granulosa cells are 
capable of synthesising many of the components of the basal lamina (Rodgers et al. 2000). The presence of increasing CTGF mRNA and protein during follicle growth to the PO stage could provide a driving force to promote the collagen biosynthesis necessary for expansion of the basal lamina. By the time, the CTGF expression declines, follicles have reached close to their maximum size so that further ECM synthesis should be unnecessary. If we assume that the decline in CTGF expression is regulated by rising sensitivity to $\mathrm{FSH}$ in the granulosa, it is possible that the gradient in CTGF expression across the granulosa compartment may reflect local differences in FSH receptors. These results may reflect the dominant role of FSH and oestradiol as regulators of granulosa cell differentiation, and demonstrate a divergence between P450 arom and CTGF mRNA expression in PO follicles.

We also show that the residual CTGF mRNA and protein in the PO follicle is strongest in the cumulus cells, the same cells that exhibit the lowest $\mathrm{P} 450_{\text {arom }}$ mRNA expression, and protein levels (Turner et al. 2002). Higher CTGF in these cells may result from the action of GDF-9 secreted by the oocyte, which we previously showed to enhance CTGF mRNA in vitro (Harlow et al. 2002). Indeed, a concentration gradient of GDF-9 as distance from the oocyte increases has been proposed (Vitt \& Hsueh 2001). However, since GDF-9 synergises with FSH to downregulate CTGF mRNA, this stimulatory effect of GDF-9 could only occur in the absence of appreciable $\mathrm{FSH}$ or $\mathrm{FSH}$ receptors. Evidence for the expression of FSH receptors in rat cumulus cells is scant, but Magnusson et al. (1982) showed responsiveness of rat cumulus cells to FSH in terms of progesterone stimulation, and bovine oocyte cumulus complexes responded to FSH by expanding in size (Van Tol et al. 1996). However, there are oocytesecreted factors, such as BMP-15 that downregulates FSH receptors (Otkay et al. 1997) and BMP-6 that downregulates FSH-induced cAMP by suppressing adenylate cyclase (Otsuka et al. 2001). Further studies on the expression of FSH receptor, FSH availability and ER isotypes in cumulus cells together with the effects of other oocyte-derived factors are required to confirm cause and consequence of elevated CTGF in the cumulus oophorus. Studies of the effect of ER antagonists on cumulus expansion and CTGF expression in vivo might also provide further mechanistic insight. Given the importance of the ECM in the structure and function of the cumulus, and the role of FSH in regulating paracrine interactions via transzonal processes between the oocyte and cumulus (Albertini et al. 2001), it is likely that CTGF may play a unique role in cell-cell communication within this highly specialised follicular compartment.

An additional intraovarian role of CTGF may relate to postovulatory angiogenesis (Brigstock 2002). Wandji et al. (2000) noted increased CTGF mRNA and protein around vascular endothelial cells in pig ovarian follicles and in association with migrating endothelial cells in the corpus luteum. We have also observed residual presence of CTGF protein in the most antrally located granulosa cells of periovulatory rat follicles which mirrors the pattern of
mRNA expression (Slee et al. 2001). This, with sustained expression by adluminal luteal cells noted in the newly formed rat (Slee et al. 2001) and human corpus luteum (Duncan et al. 2005), further emphasises a likely angiogenic role for CTGF in corpus luteum formation.

In conclusion, we show both in vivo and in vitro that CTGF

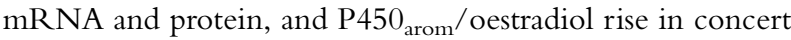
during early follicular development up to the LA stage of follicular development. The evidence suggests that oestradiol, at least in part, drives the increase in CTGF. During PO development, the role of oestradiol, under the influence of FSH, switches to suppression of CTGF. The negative spatiotemporal relationship between $\mathrm{P} 450_{\text {arom }}$ and CTGF in the PO follicle extends across the follicle wall, such that antrally located and cumulus granulosa cells show low P450 arom but high CTGF gene and protein expression. The particular relevance of CTGF to cumulus cell biology remains to be determined but it could be involved in cumulus expansion or paracrine communication between cumulus cells and oocyte.

\section{Acknowledgements}

We thank Fibrogen, Inc., San Francisco for providing the rhCTGF and Dr David Brigstock, Center for Cell and Vascular Biology, Children's Research Institute, Columbus, $\mathrm{OH} 43205$, USA for providing the CTGF antibody.

\section{Funding}

This study was supported by MRC Programme Grant 000066. There is no conflict of interest that would prejudice the impartiality of this study.

\section{References}

Albertini DF, Combelles CMH, Benecchi E \& Carabatsos MJ 2001 Cellular basis for paracrine regulation of ovarian follicle development. Reproduction $121647-653$

Berkholtz CB, Lai BE, Woodruff TK \& Shea LD 2006 Distribution of extracellular matrix proteins type I collagen, type IV collagen, fibronectin and laminin in mouse folliculogenesis. Histochemistry and Cell Biology 126 583-592.

Brigstock DR 1999 The connective tissue growth factor/cysteine-rich 61/nephroblastoma overexpressed (CCN) family. Endocrine Reviews 20 189-206.

Brigstock DR 2002 Regulation of angiogenesis and endothelial cell function by connective tissue growth factor (CTGF) and cysteine-rich 61 (CYR61). Angiogenesis 5 153-165.

Duncan MR, Frazier KS, Abramson S, Williams S, Klapper H, Huang X \& Grotendorst GR 1999 Connective tissue growth factor mediates transforming growth factor $\beta$-induced collagen synthesis: down-regulation by cAMP. FASEB Journal 13 1774-1786.

Duncan WC, Hillier SG, Gay E, Bell J \& Fraser HM 2005 Connective tissue growth factor expression in the human corpus luteum: paracrine regulation by human chorionic gonadotropin. Journal of Clinical Endocrinology and Metabolism 90 5366-5376. 
Eguchi T, Kubota S, Kondo S, Shimo T, Hattori T, Nakanishi T, Kuboki T, Yatani H \& Takigawa M 2001 Regulatory mechanism of human connective tissue growth factor $(\mathrm{CTGF} / \mathrm{Hcs} 24)$ gene expression in a human chondrocytic cell line, HCS-2/8. Journal of Biochemistry (Tokyo) 130 79-87.

Fan WH, Pech M \& Karnovsky MJ 2000 Connective tissue growth factor (CTGF) stimulates vascular smooth muscle cell growth and migration in vitro. European Journal of Cell Biology 79 915-923.

Fujii T, Hoover DJ \& Channing CP 1983 Changes in inhibin activity, and progesterone, oestrogen and androstenedione concentrations, in rat follicular fluid throughout the oestrous cycle. Journal of Reproduction and Fertility 69 307-314.

Goppelt-Struebe M, Hahn A, Iwanciw D, Rehm M \& Banas B 2001 Regulation of connective tissue growth factor (ccn2; $\operatorname{ctg} f)$ gene expression in human mesengial cells: modulation by HMG CoA reductase inhibitors (statins). Molecular Pathology 54 176-179.

Harlow CR, Davidson L, Burns KH, Yan C, Matzuk MM \& Hillier SG 2002 Follicle-stimulating hormone and transforming growth factor beta superfamily members regulate granulosa cell connective tissue growth factor gene expression in vitro and in vivo. Endocrinology 143 3316-3325.

Harlow CR, Rae M, Davidson L, Trackman PC \& Hillier SG 2003 Lysyl oxidase gene expression and enzyme activity in the rat ovary: regulation by follicle-stimulating hormone, androgen and transforming growth factor- $\beta$ superfamily members in vitro. Endocrinology 144 154-162.

Hillier SG \& de Zwart FA 1982 Androgen/antiandrogen modulation of cyclic AMP-induced steroidogenesis during granulosa cell differentiation in tissue culture. Molecular and Cellular Endocrinology 28 347-361.

Hillier SG, Zeleznik AJ, Knazek RA \& Ross GT 1980 Hormonal regulation of preovulatory follicle maturation in the rat. Journal of Reproduction and Fertility 60 219-229.

Hong HH, Uzel MI, Duan C, Sheff MC \& Trackman PC 1999 Regulation of lysyl oxidase, collagen, and connective tissue growth factor by TGF-beta1 and detection in human gingival fibroblasts. Laboratory Investigation $\mathbf{7 9}$ $1655-1667$.

Hsueh AJW, Adashi EY, Jones PBC \& Welsh TH Jr 1984 Hormonal regulation of the differentiation of cultured ovarian granulosa cells. Endocrine Reviews 5 76-127.

Magnusson C, Billig H, Eneroth P, Roos P \& Hillensjo T 1982 Comparison between the progestin secretion responsiveness to gonadotrophins of rat cumulus and mural granulosa cells in vitro. Acta Endocrinologica 101 611-616.

Otkay K, Briggs D \& Gosden RG 1997 Ontogeny of follicle-stimulating hormone receptor gene expression in isolated human ovarian follicles. Journal of Clinical Endocrinology and Metabolism 82 3748-3751.

Otsuka F, Moore RK \& Shimasaki S 2001 Biological function and cellular mechanism of bone morphogenetic protein-6 in the ovary. Journal of Biological Chemistry 276 32889-32895.
Pereira RC, Durant D \& Canalis E 2000 Transcriptional regulation of connective tissue growth factor by cortisol in osteoblasts. American Journal of Physiology, Endocrinology and Metabolism 279 E570-E576.

Rageh MAE, Moussad EE-DA, Wilson AK \& Brigstock DR 2001 Steroidal regulation of connective tissue growth factor (CCN2; CTGF) synthesis in the mouse uterus. Journal of Clinical Pathology: Molecular Pathology 54 338-346.

Rodgers RJ, Irving-Rodgers HF \& van Wezel IL 2000 Extracellular matrix in ovarian follicles. Molecular and Cellular Endocrinology 163 73-79.

Rosenfeld CS, Wagner JS, Roberts RM \& Lubahn DB 2001 Intraovarian actions of oestrogen. Reproduction 122 215-226.

Sampath D, Zhu Y, Winneker RC \& Zhang Z 2001 Aberrant expression of Cyr61, a member of the CCN (CTGF/Cyr61/Cef10/NOVH) family, and dysregulation by 17 beta-estradiol and basic fibroblast growth factor in human uterine leiomyomas. Journal of Clinical Endocrinology and Metabolism 86 1707-1715.

Slee RB, Hillier SG, Largue P, Harlow CR, Miele G \& Clinton M 2001 Differentiation-dependent expression of connective tissue growth factor and lysyl oxidase messenger ribonucleic acids in rat granulosa cells. Endocrinology 142 1082-1089.

Smith-Mungo LI \& Kagan HM 1998 Lysyl oxidase: properties, regulation and multiple functions in biology. Matrix Biology 16 387-398.

Turner KJ, Macpherson S, Millar MR, McNeilly AS, Williams K, Cranfield M, Groome NP, Sharpe RM, Fraser HM \& Saunders PTK 2002 Development and validation of a new monoclonal antibody to mammalian aromatase. Journal of Endocrinology 172 21-30.

Van Tol HT, van Eijk MJ, Mummery CL, van den Hurk R \& Bevers MM 1996 Influence of FSH and hCG on the resumption of meiosis of bovine oocytes surrounded by cumulus cells connected to membrana granulosa. Molecular Reproduction and Development 45 218-224.

Vitt UA \& Hsueh AJ 2001 Stage-dependent role of growth differentiation factor-9 in ovarian follicle development. Molecular and Cellular Endocrinology 183 171-177.

Wandji SA, Gadsby JE, Barber JA \& Hammond JM 2000 Messenger ribonucleic acids for MAC25 and connective tissue growth factor (CTGF) are inversely regulated during folliculogenesis and early luteogenesis. Endocrinology 141 2648-2657.

Xu J, Smock SL, Safadi FF, Rosenzweig AB, Odgren PR, Marks SC Jr, Owen TA \& Popoff SN 2000 Cloning the full-length cDNA for rat connective tissue growth factor: implications for skeletal development. Journal of Cellular Biochemistry 77 103-115.

\section{Received in final form 16 October 2006 Accepted 23 October 2006 Made available online as an Accepted Preprint 27 October 2006}

